Quim. Nova, Vol. 36, No. 1, 74-78, 2013

\title{
OXIDAÇÃO DE GLICEROL SOBRE NANOPARTÍCULAS DE OURO SUPORTADAS EM CARVÃO ATIVADO: MONITORAMENTO QUIMIOMÉTRICO DA REAÇÃO POR ESI-MS E MIR
}

\author{
Cleiton A. Nunes e Mário C. Guerreiro* \\ Departamento de Química, Universidade Federal de Lavras, CP 3037, 37200-000 Lavras - MG, Brasil
}

Recebido em 28/3/12; aceito em 27/7/12; publicado na web em 28/11/12

\begin{abstract}
GLYCEROL OXIDATION OVER GOLD NANOPARTICLES SUPPORTED ON ACTIVATED CARBON: CHEMOMETRIC MONITORING OF THE REACTION BY ESI-MS AND MIR. A study on the monitoring of glycerol oxidation catalyzed by gold nanoparticles supported on activated carbon under mild conditions by chemometric methods is presented. The reaction was monitored by mass spectrometry-electrospray ionization (ESI-MS) and comparatively by mid infrared spectroscopy (MIR). Concentration profiles of reagent and products were determined by chemometric tools such as Principal Component Analysis (PCA), Evolving Factor Analysis (EFA) and Multivariate Curve Resolution (MCR). The gold nanoparticle catalyst was relatively active in glycerol oxidation, favoring formation of high added value products. It was found that the reaction stabilization was reached at four hours, with approximately $70 \%$ glycerol conversion and high selectivity for glycerate.
\end{abstract}

Keywords: glycerol; gold; chemometrics.

\section{INTRODUÇÃO}

A síntese de nanopartículas metálicas é hoje um dos campos da Química em grande desenvolvimento. Devido a seus pequenos tamanhos e às grandes áreas superficiais específicas, as nanopartículas exibem propriedades que diferem significativamente das do material na forma macroestruturada. Um grande número de aplicações importantes das nanopartículas metálicas é reportado na literatura, tais como na eletrônica, no armazenamento de informações em alta densidade e em dispositivos de fotoluminescência e eletroluminescência. ${ }^{1}$

Nesta vasta gama de aplicações, o uso de nanopartículas metálicas como catalisadores em reações orgânicas tem atraído grande atenção nos últimos anos. O interesse nos catalisadores de nanopartículas metálicas tem crescido consideravelmente, devido a essa classe de catalisadores se apresentar como uma das mais promissoras soluções para tornar as reações mais eficientes sob condições brandas e ambientalmente corretas no contexto de Química Verde.

Entre os catalisadores à base de nanopartículas, os produzidos a partir de metais nobres suportados representam um grande grupo de catalisadores heterogêneos de grande importância tecnológica. ${ }^{1}$ O ouro tem sido o principal metal usando no preparo deste tipo de catalisador, apesar de nanopartículas de outros metais nobres, tais como platina, paládio e prata também apresentarem considerável atividade catalítica. $^{2}$

Entre as reações nas quais os catalisadores à base de nanopartículas de metais nobres têm apresentado atividade, as que envolvem a conversão do glicerol em produtos de alto valor agregado vêm estimulando uma série de pesquisas explorando os processos envolvidos. Esse interesse é justificado pelo recente avanço das pesquisas e da crescente produção de biodiesel nos últimos anos. Nesse cenário, passou-se a ter uma maior preocupação com o destino do glicerol, o qual veio a ser produzido em grande escala como coproduto na produção desse combustível. Pesquisas recentes têm demonstrado o alto potencial do glicerol como material de partida para a obtenção de uma grande variedade de compostos químicos de interesse industrial, sendo que os catalisadores de metais nobres nanoparticulados têm se revelado como eficientes em uma série de reações envolvendo tais conversões. ${ }^{2-4}$

*e-mail: guerreiro@dqi.ufla.br
Um processo que tem despertando grande interesse envolve a oxidação de glicerol a glicerato e/ou a glicolato, ${ }^{5}$ os quais podem ser posteriormente convertidos em seus respectivos ácidos, glicérico e glicólico. São relatadas várias aplicações para o ácido glicérico e seus derivados, tais como estimulante do fígado e colesterolítico, acelerador da oxidação de etanol e acetaldeído in vivo, além de servir de material de partida para fabricação de surfactantes funcionais e polímeros. ${ }^{6} \mathrm{O}$ ácido glicólico tem uma produção global anual que chega a alguns milhares de toneladas. Sua principal aplicação está na área cosmética, sobretudo em produtos dermatológicos. ${ }^{7}$ Frente a isso, a produção de ácido glicérico (ou glicerato) e ácido glicólico (ou glicolato) a partir de glicerol representaria avanços no campo ambiental, pois seria utilizada uma matéria-prima renovável proveniente de um coproduto da produção do biodiesel, e até mesmo na esfera econômica, visto que o uso do glicerol residual poderia representar uma diminuição no custo da matéria-prima diante da previsão de sua grande oferta com o avanço dos programas de produção de biodiesel.

Neste trabalho é apresentado um estudo acerca do monitoramento da oxidação de glicerol catalisada por nanopartículas de ouro suportadas em carvão ativado usando métodos quimiométricos. O catalisador foi caracterizado por espectrofotometria UV-VIS e por microscopia eletrônica de transmissão (TEM). A reação foi monitorada por espectrometria de massas com ionização por eletrospray (ESI-MS) e comparativamente por espectroscopia no infravermelho médio (MIR). Os perfis de concentração do substrato e dos produtos da reação foram determinados por métodos quimiométricas, como análise de componentes principais (PCA), análise de fatores evoluintes (EFA) e resolução multivariada de curvas (MCR). Essas ferramentas, já bem descritas na literatura, ${ }^{8-10}$ permitem determinar o número de espécies puras presentes no sistema reacional, além de estimar seus perfis de concentração ao longo da reação, bem como viabilizar sua identificação a partir da estimativa dos respectivos espectros puros.

\section{PARTE EXPERIMENTAL}

\section{Síntese do catalisador}

O catalisador foi preparado pelo método sol-ouro. ${ }^{11}$ Inicialmente preparou-se uma solução aquosa de $\mathrm{HAuCl}_{4} \cdot 3 \mathrm{H}_{2} \mathrm{O}\left(50,0 \mathrm{mg} \mathrm{L}{ }^{-1}\right)$ 
seguida da adição de álcool polivinílico (solução aquosa 1,0 \% m/v). O ouro foi reduzido através da adição de $\mathrm{NaBH}_{4} 0,1 \mathrm{~mol} \mathrm{~L}^{-1}$ sob agitação em quantidade suficiente para se ter razão molar 4:1 em relação ao ouro. O carvão ativado foi então adicionado sobre a suspensão de nanopartículas em quantidade suficiente para se ter $1,0 \%$ em peso de ouro com relação ao suporte. A agitação foi mantida por $2 \mathrm{~h}$. Em seguida, o material foi filtrado em filtro de papel e lavado com água destilada até a completa remoção dos íons $\mathrm{Cl}^{-}$(teste com $\mathrm{AgNO}_{3}$ 0,1 $\left.\mathrm{mol} \mathrm{L}{ }^{-1}\right)$. Finalmente, o material foi seco em estufa a $120^{\circ} \mathrm{C}$ por $24 \mathrm{~h}$.

\section{Caracterização do catalisador}

As nanopartículas de ouro, ainda em solução, foram caracterizadas por espectrofotometria UV-Vis antes de serem suportadas no carvão ativado. Os espectros foram obtidos de 400 a $800 \mathrm{~nm}$ em espectrofotômetro Shimadzu UV-1800. A partir dessa análise é possível se obter uma estimativa da dimensão das nanopartículas presentes na solução, com base no comprimento de onda da absorção máxima devido ao efeito de ressonância de plasma de superfície. ${ }^{12}$

A morfologia do catalisador foi analisada por microscopia eletrônica de transmissão, que fornece informações não só sobre a morfologia do material, mas também permite determinar o diâmetro médio das nanopartículas depositadas sobre o suporte. O preparo da amostra consistiu em se obter uma suspensão do catalisador em metanol, na concentração de $5,0 \mathrm{mg} \mathrm{mL}^{-1}$. Em seguida, uma gota dessa solução foi depositada sobre uma tela de cobre específica para este tipo de análise. O solvente foi evaporado em estufa a $70{ }^{\circ} \mathrm{C}$ por 10 min e a amostra submetida à análise em microscópio Zeiss EM-109.

\section{Reação de oxidação do glicerol}

A reação de oxidação do glicerol foi realizada a $50{ }^{\circ} \mathrm{C}$, em meio aquoso, usando $\mathrm{H}_{2} \mathrm{O}_{2}(30 \%$ v/v) como agente oxidante. Em um erlenmeyer com tampa foram adicionados $30,0 \mathrm{mg}$ do catalisador, $150,0 \mathrm{mg}$ de $\mathrm{NaOH}, 4,75 \mathrm{~mL}$ de água destilada, $100,0 \mu \mathrm{L}$ de glicerol e $150,0 \mu \mathrm{L}$ de $\mathrm{H}_{2} \mathrm{O}_{2}$. Em intervalos de $1 \mathrm{~h}$ retirou-se uma alíquota para análise por ESI-MS e MIR.

\section{Análise por ESI-MS}

Uma alíquota de $10,0 \mu \mathrm{L}$ retirada do meio reacional foi adicionada a 750,0 $\mu \mathrm{L}$ de água Milli-Q e 750,0 $\mu \mathrm{L}$ de metanol, sendo a solução resultante analisada por ESI-MS no modo negativo. Os espectros foram obtidos em espectrômetro de massas Agilent 1100LC/MSD-Trap. Uma avaliação sobre os principais produtos da reação, bem como a identificação de cada um, foi realizada a partir dos respectivos espectros obtidos por MS/MS e por comparação com trabalho anterior. ${ }^{13}$

\section{Análise por MIR}

Comparativamente a reação foi monitorada por MIR. A análise foi realizada usando-se acessório de refletância total atenuada (ATR), colocando-se uma gota de amostra sobre o cristal de ATR para obtenção dos espectros. Os espectros foram obtidos em espectrômetro de infravermelho Digilab FTS-3000 na região entre 400 e $4000 \mathrm{~cm}^{-1}$ com resolução de $4 \mathrm{~cm}^{-1}$.

\section{Análises quimiométricas}

Os dados espectrais (fingerprints) obtidos ao longo da reação por ESI-MS e MIR foram analisados usando PCA, EFA e MCR, objetivando obter os perfis de concentração do glicerol e dos principais produtos de oxidação ao longo da reação.

As matrizes de dados foram organizadas com as amostras dispostas em linhas e as variáveis em colunas. As variáveis consideradas para os espectros de massas foram a intensidade de cada sinal $\mathrm{m} / \mathrm{z}$, no modo negativo e para os espectros de infravermelho, a absorbância em cada número de onda.

Os cálculos foram executados usando MCR-ALS_Toolbox ${ }^{14} \mathrm{em}$ ambiente Matlab.

\section{RESULTADOS E DISCUSSÃO}

\section{Caracterização do catalisador}

Um importante indício da formação das nanopartículas de ouro pelo método sol-ouro é o desenvolvimento de uma coloração vermelha violácea na solução de $\mathrm{HAuCl}_{4}$ ao se adicionar o agente redutor (neste caso, $\mathrm{NaBH}_{4}$ ). Esta coloração é causada pelo efeito de ressonância de plasma de superfície, o qual é observado principalmente em superfícies de metais nanoparticulados e ocorre quando a radiação eletromagnética interage com elétrons livres do metal, sendo o comprimento de onda de máxima absorção dependente do tamanho das nanopartículas. ${ }^{15}$ Uma estimativa do tamanho aproximado das nanopartículas pode ser feita com base no comprimento de onda de máxima absorção da solução contendo as nanopartículas metálicas. Foram obtidos espectros UV-Vis para a solução de $\mathrm{HAuCl}_{4}$ antes e depois da adição do agente redutor. Os espectros (Figura 1S, material suplementar) mostram o surgimento de uma banda de absorção em comprimentos de onda ao redor de $530 \mathrm{~nm}$ após a adição de $\mathrm{NaBH}_{4}$, indicando a formação de nanopartículas de aproximadamente $10 \mathrm{~nm} \cdot{ }^{12}$

Após o processo de síntese, o catalisador foi caracterizado por TEM. A micrografia obtida (Figura $2 \mathrm{~S}$, material suplementar) mostra claramente a presença das nanopartículas dispersas na superfície do carvão ativado. A imagem obtida para o carvão ativado que passou pelas mesmas etapas de preparo do catalisador, mas na ausência de ouro, mostra a ausência dos pontos escuros referentes às nanopartículas. $\mathrm{O}$ diâmetro médio das nanopartículas foi determinado por medida direta nas micrografias. Foram medidas 50 nanopartículas, sendo o resultado expresso como a média. $\mathrm{O}$ diâmetro médio obtido foi de $8.9 \mathrm{~nm}$ como esperado para o método usado ${ }^{11}$ e indicado pelos espectros eletromagnéticos na região do visível (Figura 1S, material suplementar).

\section{Oxidação do glicerol sobre nanopartículas de ouro}

É relatado que a primeira etapa para a formação de produtos oxidados a partir do glicerol em meio alcalino envolve inicialmente a desprotonação de uma hidroxila do glicerol para formar o intermediário glicerolato, o qual é em seguida desidrogenado a gliceraldeído. ${ }^{16}$ Mecanismos descritos na literatura sugerem a formação de glicerato através da oxidação do gliceraldeído e que este pode ser oxidado para formar o tartronato. $\mathrm{O}$ glicolato pode ser obtido via descarboxilação do tartronato. ${ }^{11,17}$

Estudos sobre o mecanismo dessa reação sugerem que as etapas reacionais ocorridas na presença de hidroxila apresentam barreiras de ativação consideravelmente menores e mais favoráveis que os realizados em sua ausência. Além disso, foi demostrado que os átomos de oxigênio incorporados no glicerol durante sua oxidação são provenientes da hidroxila (base promotora) em vez do agente oxidante. Cálculos por DFT (Teoria do Funcional da Densidade) indicaram que o peróxido de hidrogênio presente no meio reacional é decomposto em $\mathrm{OH}^{-}$, promovendo a regeneração da base promotora. ${ }^{13}$

Um possível esquema para esta reação, baseado nos relatos da literatura, é apresentado na Figura 3S, material suplementar. 
Para o estudo cinético da oxidação do glicerol, a reação foi monitorada durante $11 \mathrm{~h}$, sendo o meio reacional analisado por ESI-MS e MIR em intervalos de $1 \mathrm{~h}$.

A Figura 1 apresenta o perfil das intensidades dos sinais $\mathrm{m} / \mathrm{z}$ obtidos por ESI-MS (-) para o glicerol e para os produtos da reação em função do tempo. A identificação dos sinais $\mathrm{m} / \mathrm{z}$ para cada espécie da reação foi feita a partir dos respectivos espectros obtidos por MS/MS e por comparação com trabalho anterior. ${ }^{13}$ Uma forte diminuição do sinal referente ao glicerol é observada até por volta de 4 h, quando então se verifica uma tendência à estabilização do sinal. Paralelamente, verifica-se a formação dos produtos já no início da reação. Um aumento brusco do sinal referente ao gliceraldeído é observado em um primeiro momento da reação, o qual diminui e é acompanhado pelo aumento gradual do sinal referente ao glicerato. Isso corrobora o esquema proposto para a oxidação do glicerol apresentado na Figura 3S, material suplementar, o qual sugere a formação inicial do gliceraldeído e sua posterior conversão no glicerato. Os sinais referentes aos produtos glicolato e tartronato apresentaram-se menos intensos e estabilizados logo no início da reação.

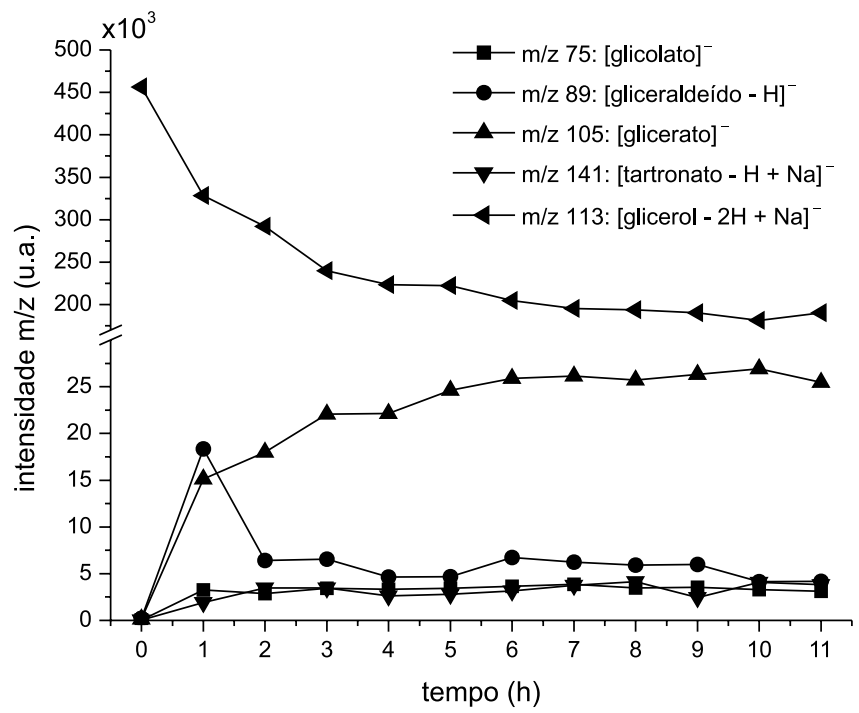

Figura 1. Cinética da oxidação do glicerol monitorada por ESI-MS (-)

Para determinar as frações das espécies durante a reação, foram aplicados métodos quimiométricos aos dados espectrais obtidos por ESI-MS e MIR.

Inicialmente o número de espécies no sistema foi determinado por EFA e PCA. A indicação do número de espécies no sistema por EFA é feito com base no número de linhas de autovalores que emergem do ruído, e por PCA, com base nos autovalores das componentes principais que mais se destacam em termos de magnitude e por sua estabilização em função das componentes principais. ${ }^{10}$

EFA é baseada em repetitivas PCAs das submatrizes (espectros) que compõem o conjunto de dados obtido ao longo do processo. A expressão gráfica de resultados obtidos por EFA representa os autovalores obtidos pela análise dos espectros no sentido em que o processo ocorre (análise direta), bem como os autovalores obtidos pela análise no sentido contrário ao que o processo é realizado (análise inversa), Figura 2. Quando uma nova espécie aparece, um autovalor (representado por uma linha) emerge do ruído na análise direta. Por outro lado, a análise inversa permite conhecer a região em que cada espécie desaparece ou passa a ter uma baixa contribuição no sistema, sendo que a primeira espécie que emerge na análise direta será a primeira espécie a desaparecer na análise inversa. ${ }^{8}$ Os resultados obtidos por EFA são imprescindíveis para uma determinação posterior dos perfis
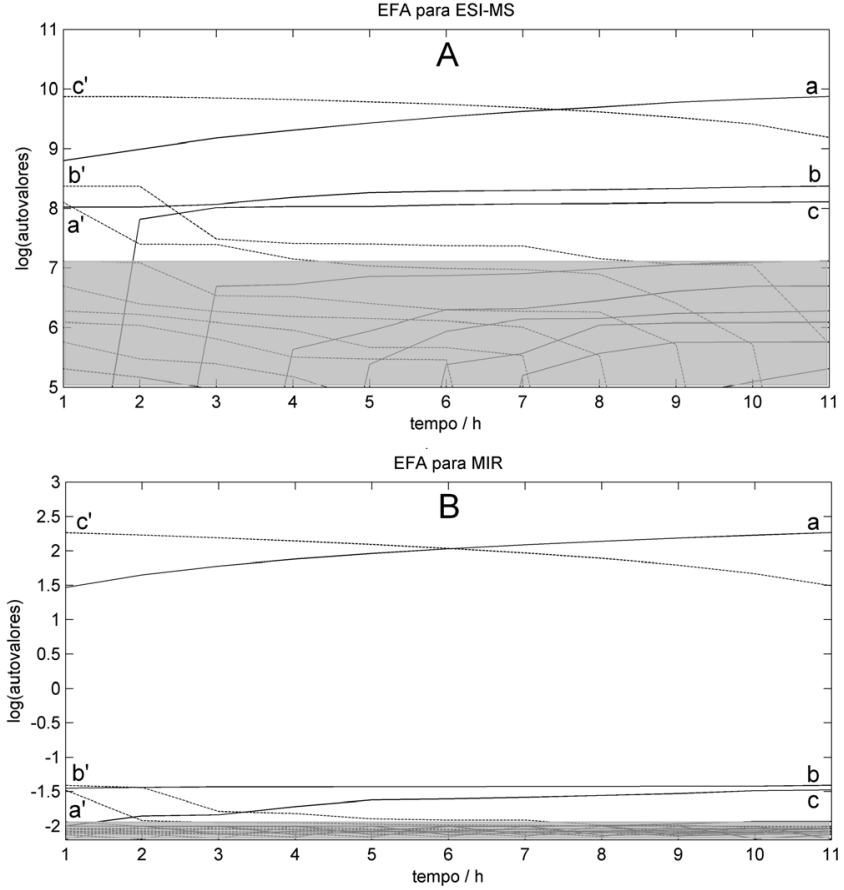

Figura 2. EFA para os dados espectroscópicos de ESI-MS (A) e MIR (B). a, b e c: autovalores para as três principais espécies na análise direta. $a^{\prime}, b^{\prime} e$ c': autovalores para as três principais espécies na análise inversa

de concentração das espécies por MCR.

O gráfico EFA obtido a partir dos espectros ESI-MS (Figura 2a) mostra três espécies emergindo do ruído (parte sombreada). Duas delas estão presentes desde o primeiro momento da reação, enquanto que a outra se destaca um pouco depois, em aproximadamente 1,5 h. A primeira espécie tende a ter sua intensidade diminuída em aproximadamente $4 \mathrm{~h}$ de reação. A segunda espécie tem sua intensidade diminuída bruscamente logo início do processo, mas permanece com fraca intensidade até aproximadamente $8 \mathrm{~h}$. A terceira espécie permanece no sistema com alta intensidade até o final do processo. O gráfico EFA para os dados obtidos por MIR (Figura 2b) mostra resultados que corroboram os obtidos por ESI-MS, apresentando comportamento semelhante para as três espécies.

Os autovalores obtidos por PCA dos espectros ESI-MS (Tabela 1) apresentam variações pouco significantes além de três componentes principais, indicando, portanto, a contribuição de três espécies no sistema. Os autovalores obtidos por PCA dos espectros MIR (Tabela 1) também indicam a contribuição de três componentes principais no sistema, devido à baixa variação além desse ponto.

Os resultados de EFA e PCA indicaram, portanto, a contribuição de três espécies no sistema. Conforme identificação dos produtos da reação por espectrometria de massas, esperava-se que a EFA e a PCA indicassem a presença de pelo menos cinco espécies (o substrato e os quatro produtos) de acordo com Figura 1. No entanto, esses métodos indicaram a presença de apenas três. Uma hipótese que pode explicar este resultado seria a baixa concentração para dois dos produtos (glicolato e tartronato, como já esperado para este tipo de reação), ${ }^{18}$ não sendo possível a detecção de suas contribuições nas análises dos dados por EFA e PCA. Entretanto, isso não impossibilitou a determinação dos perfis de concentração das três espécies principais por MCR.

Após determinação do número de espécies por EFA e PCA, seus respectivos perfis de concentração e espectros de massas foram estimados por MCR. A identificação da espécie correspondente a cada perfil de concentração obtido por MCR foi feita através dos respectivos espectros de massas estimados (Figura 3c) e por comparação com 
Tabela 1. Autovalores obtidos por PCA dos espectros ESI-MS e MIR

\begin{tabular}{ccc}
\hline $\begin{array}{c}\text { Componente } \\
\text { principal }\end{array}$ & Autovalor & $\begin{array}{c}\text { Diferença entre } \\
\text { autovalores }\end{array}$ \\
\hline 1 & ESI-MS & 12,66 \\
2 & 25,38 & 2,73 \\
3 & 12,72 & 1,20 \\
4 & 9,99 & 0,45 \\
5 & 8,79 & 0,77 \\
6 & 8,34 & 0,54 \\
7 & 7,57 & \\
\hline & 7,03 & 39,80 \\
\hline 1 & MIR & 13,35 \\
2 & 89,26 & 3,29 \\
3 & 49,46 & 0,80 \\
4 & 36,11 & 0,36 \\
5 & 32,82 & 1,12 \\
6 & 32,01 & \\
7 & 31,65 & \\
\hline
\end{tabular}

trabalho anterior, ${ }^{13}$ os quais indicaram as espécies como glicerol $(\mathrm{m} / \mathrm{z}$ $113($ glicerol $-2 \mathrm{H}+\mathrm{Na})$ ), glicerato $(\mathrm{m} / \mathrm{z}$ 105) e gliceraldeído $(\mathrm{m} / \mathrm{z}$ 89). Entretanto, observou-se que alguma informação sobre o glicolato e o tartronato estava presente nos perfis de concentração referentes ao gliceraldeído e ao glicerato, devido à presença (com baixa intensidade) dos sinais com $\mathrm{m} / \mathrm{z} 75$ e 141 nos espectros estimados. Isso pode se justificado pelo fato de terem sido consideradas apenas três espécies nos cálculos por MCR, conforme sugerido por EFA e PCA. Apesar de não terem contribuído com informação significativa para suas detecções por EFA e PCA (e consequentemente por MCR), os sinais $\mathrm{m} / \mathrm{z}$ do glicolato e tartronato estavam presentes nos espectros de massas medidos para o meio reacional e eram esperados nos espectros estimados por MCR. Como não puderam ser estimados separadamente, esses sinais foram estimados juntamente com os sinais das outras espécies. Entretanto, devido às baixas concentrações do glicolato e do tartronato, as estimativas dos perfis de concentração para glicerol, gliceraldeído e glicerato não foram prejudicadas, pois os perfis de concentração estimados por MCR (Figuras 3a e b) corroboraram os obtidos a partir das intensidades dos sinais $\mathrm{m} / \mathrm{z}$ dos produtos (Figura 1). Os perfis indicaram que uma estabilização da reação foi alcançada em torno de $4 \mathrm{~h}$, tendo um remanescente de glicerol de aproximadamente $30 \%$ e uma concentração de cerca de $60 \%$ de glicerato. Também ficou evidente uma alta produção de gliceraldeído no início da reação que, logo em seguida, foi consumido e convertido nos produtos de oxidação, conforme sugerido no esquema apresentado (Figura 3S, material suplementar).

Percentuais de conversão semelhantes também foram relatados para a oxidação de glicerol sob altas pressões de $\mathrm{O}_{2}$, usando catalisadores à base de nanopartículas de paládio suportadas em óxido de titânio. ${ }^{19}$ Nesse caso, uma alta seletividade para glicerato também foi verificada.

\section{CONCLUSÃO}

O catalisador à base de nanopartículas de ouro suportadas em carvão ativado é consideravelmente ativo na oxidação de glicerol, favorecendo a formação de produtos de interesse tecnológico.
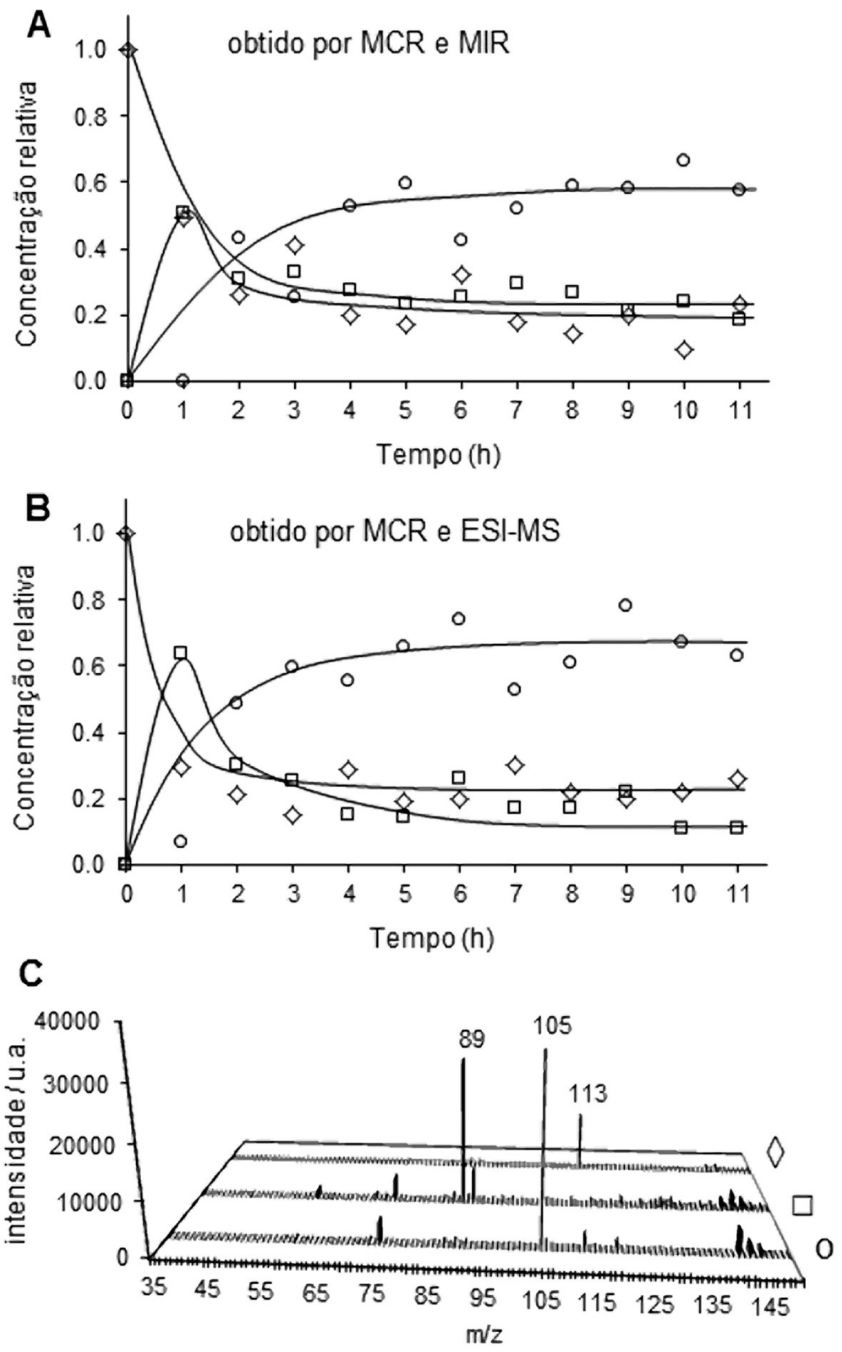

Figura 3. Perfis de concentração para as principais espécies presentes na oxidação do glicerol obtidos MCR a partir dos dados de MIR (a) e ESI-MS (b). Os espectros de massas (c) para as espécies foram estimados por MCR a partir dos dados de ESI-MS

Algumas condições operacionais observadas neste estudo mostraram-se vantajosas sob um ponto de vista técnico e até mesmo ambiental e econômico, como o uso de oxidante limpo $\left(\mathrm{H}_{2} \mathrm{O}_{2}\right)$, de temperatura relativamente baixa $\left(50^{\circ} \mathrm{C}\right)$ e pressão ambiente.

As ferramentas quimiométricas foram extremamente úteis na determinação dos perfis de concentração das espécies durante a reação através de análises rápidas, sem se ter, a princípio, informações quantitativas sobre o processo e sem a necessidade de se ter à disposição padrões para quantificação das principais espécies.

\section{MATERIAL SUPLEMENTAR}

Os espectros UV-Vis da solução de $\mathrm{HAuCl}_{4}$ obtidos antes e após a redução de $\mathrm{NaBH}_{4}$, as micrografias obtidas por microscopia eletrônica de transmissão para o carvão ativado e para o catalisador, bem como um esquema da reação de oxidação do glicerol usando catalisador à base de nanopartículas de ouro estão disponíveis gratuitamente em http://quimicanova.sbq.org.br na forma de arquivo PDF.

\section{AGRADECIMENTOS}

À FAPEMIG, PETROBRAS, CAPES, CNPq e FINEP pelo apoio 
financeiro; ao Laboratório de Microscopia Eletrônica e à Central de Análise e Prospecção Química da UFLA pelo suporte técnico.

\section{REFERÊNCIAS}

1. Scirè, S.; Crisafulli, C.; Giuffrida, S.; Mazza, C.; Riccobene, P. M.; Pistone, A.; Ventimiglia, G.; Bongiorno, C.; Spinella, C.; Appl. Catal., A 2009, 367, 138.

2. Zhou, C.; Beltramini, J. N.; Fan, Y. X.; Lu, G. Q.; Chem. Soc. Rev. 2008, $37,527$.

3. Zheng, Y.; Chen, X.; Shen Y.; Chem. Rev. 2008, 108, 5253.

4. Carrettin, S.; Mcmorn, P.; Johnston, P.; Griffin, K.; Hutchings, G. J.; Chem. Commun. 2002, 7, 696.

5. Nunes, C. A.; Guerreiro, M. C.; Br PI 1002691-6, 2011.

6. Habe, H.; Fukuoka, T.; Kitamoto, D.; Sakaki, K.; Appl. Microbiol. Biot. 2009, 84, 445.

7. Cherie, M. D.; Dermatol. Ther. 2000, 13, 165.

8. Sena, M.; Collins, C. H.; Collins, K. E.; Scarminio, I. S.; Quim. Nova 2001, 24, 331.

9. Juan, A.; Tauler, R.; Crit. Rev. Anal. Chem. 2006, 36, 163.
10. Del Río, V.; Callao, M. P.; Larrechi, M. S.; Espinosa, L. M.; Ronda, J. C.; Cádiz, V.; Anal. Chim. Acta 2009, 642, 148.

11. Sankar, M.; Dimitratos, N.; Knight, D. W.; Carley, A. F.; Tiruvalam, R.; Kiely, C. J.; Thomas, D.; Hutchings, G. J.; ChemSusChem 2009, 2, 1145.

12. Prati, L.; Martra, G.; Gold Bull. 1999, 32, 96.

13. Zope, B. N.; Hibbitts, D. D.; Neurock, M.; Davis, R. J.; Science 2010, $330,74$.

14. Jaumot, J.; Gargallo, R.; Juan, A.; Tauler, R.; Chemom. Intell. Lab. Syst. $\mathbf{2 0 0 5}, 76,101$.

15. Eustis, S.; El-Sayed, M. A.; Chem. Soc. Rev. 2006, 35, 209.

16. Ketchie, W. C.; Murayama, M.; Davis, R. J.; Top. Catal. 2007, 44, 307.

17. Demirel-Gülen, S.; Lucas, M.; Claus, P.; Catal. Today 2005, 102-103, 166.

18. Ketchie, W. C.; Fang, Y. L.; Wong, M. S.; Murayama, M.; Davis. R. J.; J. Catal. 2007, 250, 94

19. Dimitratos, N.; Lopez-Sanchez, J. A.; Anthonykutty, J. M.; Brett, G.; Carley, A. F.; Tiruvalam, R. C.; Herzing, A. A.; Kiely, C. J.; Knight, D. W.; Hutchings, G. J.; Chem. Commun. 2002, 11, 696. 


\section{OXIDAÇÃO DE GLICEROL SOBRE NANOPARTÍCULAS DE OURO SUPORTADAS EM CARVÃO ATIVADO: MONITORAMENTO QUIMIOMÉTRICO DA REAÇÃO POR ESI-MS E MIR}

Cleiton A. Nunes e Mário C. Guerreiro*

Departamento de Química, Universidade Federal de Lavras, CP 3037, 37200-000 Lavras - MG, Brasil

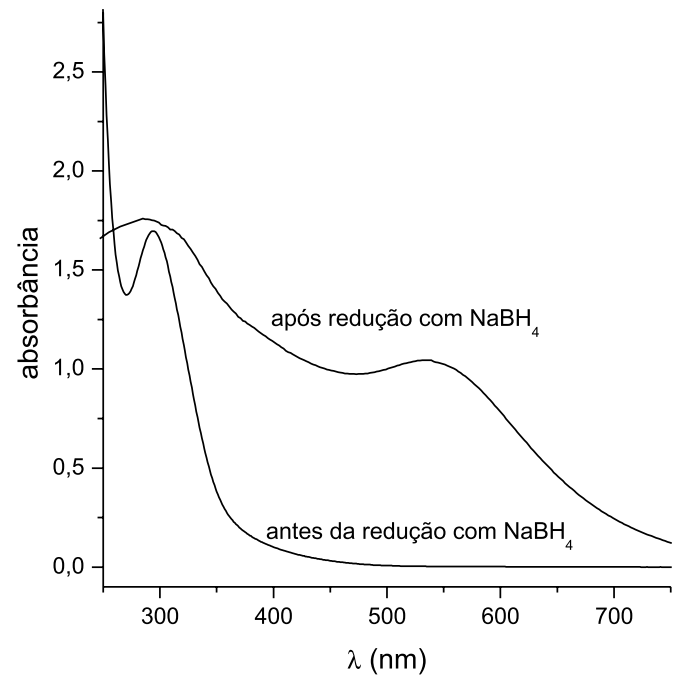

Figura 1S. Espectros UV-Vis para a solução de $\mathrm{HAuCl}_{4}$ antes e após redução com $\mathrm{NaBH}_{4}$
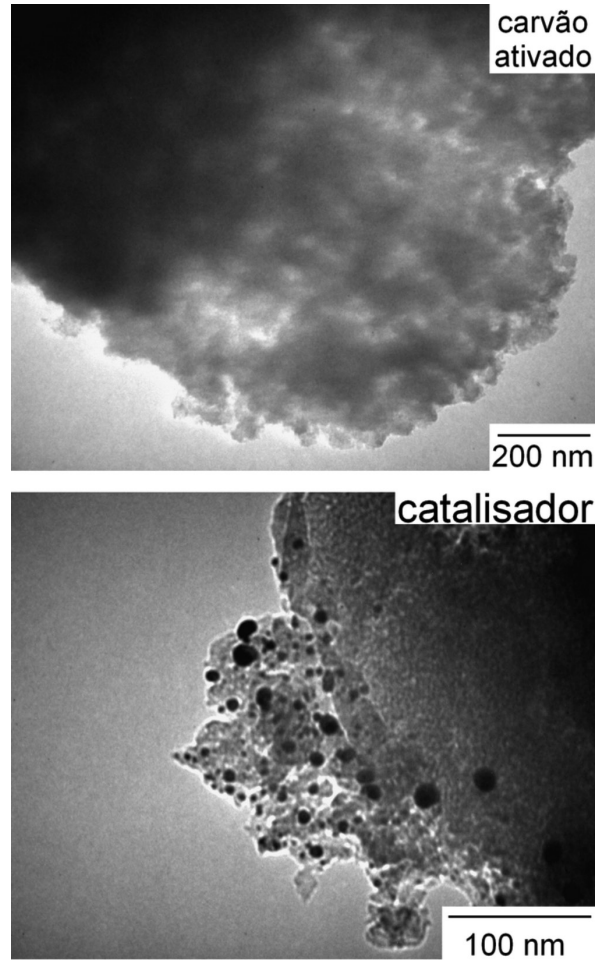

Figura 2S. Micrografias TEM para o carvão ativado tratado e para o catalisador

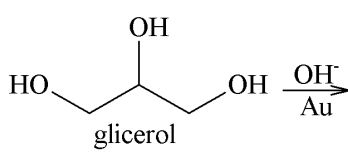<smiles></smiles><smiles>O=CC([O-])C(O)Cl</smiles>

gliceraldeído $\mathrm{Au} \mid \mathrm{OH}^{-} / \mathrm{H}_{2} \mathrm{O}_{2}$<smiles></smiles>

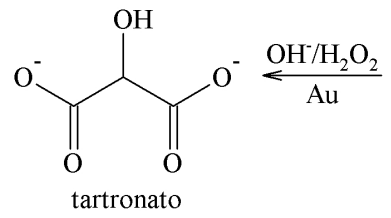<smiles>O=C([O-])C(O)CO</smiles>

Figura 3S. Esquema reacional para a oxidação do glicerol usando catalisador à base de nanopartículas de ouro 